\title{
Destruction of organo-halogenated compounds by DC non-transferred arc plasma
}

\author{
G. Bonizzoni \\ Istituto di Fisica del Plasma-Consiglio Nazionale delle Ricerche, Via Cozzi, \\ 53-Milano 20125, Italy
}

\begin{abstract}
The actual technologies for the destruction of organo-halogenated substances are reviewed and compared with the emerging plasma processes based on the non transferred arc plasma torches. The associated costs are presented.
\end{abstract}

\section{INTRODUCTION}

The halogenated waste, when incinerated without precautions, could produce toxic substances like dioxins and furans. Dioxins, are polychlorinated dibenzo-para-dioxin (PCDDs). Chlorinated dibenzodioxins (CDDs), chlorinated dibenzofurans (CDFs) and polychlorinated biphenyl (PCBs) are harmful as dioxins. PCDDs and PCDFs are chlorinated aromatic compounds, each with a triple ring structure consisting of two benzene rings interconnected to each other, respectively, by two or one oxygen atoms. During incineration, thermal breakdown of chlorinated compounds and organic materials takes place. As the gas flue leaves the primary combustion chamber, these compounds cool from $1000^{\circ} \mathrm{C}$ and subsequently condense. It's during this molecular rearrangements that dioxins are formed. The formation of dioxin commonly occurs between 650 and $300^{\circ} \mathrm{C}$, with maximum formation occurring at approximately $300^{\circ} \mathrm{C}$. To control the formation of dioxins, the incinerators rapidly cool the flue gas using a spray dryer and scrubber or some other pollution devices. However, dioxin is formed and with the presence of metal catalysts (like copper, zinc or cadmium) the concentrations of the emitted dioxin can be even greater. Actual respects point out that around the $60 \%$ of the Special Toxic Wastes is constituted from muddies (with until 25\% of suspended solid); the remaining part is constituted for around the $20.5 \%$ from liquid and for the $19.5 \%$ from solid. The aforesaid data reveal the need to arrange effective technologies of low environmental impact for the recovery, treatment and destruction of toxic wastes with diversified origin and physical states.

\section{ACTUAL TECHNOLOGIES AND ASSOCIATED COSTS [1]}

Specific treatments and destruction technologies are allowed for certain types of PCB wastes. Alternative technologies are allowed if it can be proven that their performance of these technologies are equivalent to incineration. Table 1 lists the advantages and limitations of several PCB treatment/destruction technologies while Fig. 1 lists their associated costs. Transportation costs can add \$100 to \$200 per ton. These technologies are discussed in more detail below.

\subsection{Established technologies}

\subsubsection{Incineration}

Is the standard treatment for PCB destruction, but only where the system can achieve a DRE of $99.9999 \%$. The incineration process treats organic contaminants in solids and liquids, using high temperatures to volatilize and destroy these compounds. The process generally consists of waste preparation, a waste feed

\footnotetext{
* Lecture presented at the 14th International Symposium on Plasma Chemistry, Prague, Czech Republic, 2-6 August 1999, pp. 1809-1918.
} 
Table 1 Advantages and limitations of technologies for remediating PCB-contaminated soil and sediment

\begin{tabular}{|c|c|c|c|c|c|c|c|c|}
\hline \multirow[b]{2}{*}{ Remedial technology } & \multicolumn{4}{|c|}{ Established/proven } & \multicolumn{4}{|c|}{ Emerging } \\
\hline & $\begin{array}{l}\text { Thermal } \\
\text { Incineration }\end{array}$ & $\begin{array}{l}\text { Chemical } \\
\text { desorption }\end{array}$ & $\begin{array}{l}\text { Solvent } \\
\text { dehalogenation }\end{array}$ & $\begin{array}{l}\text { Soil } \\
\text { extraction }\end{array}$ & $\begin{array}{l}\text { Solidifice } \\
\text { washing }\end{array}$ & $\begin{array}{l}\text { ation } \\
\text { stabilization }\end{array}$ & Bioremediation & Vitrification \\
\hline \multicolumn{9}{|l|}{ Advantages } \\
\hline $\begin{array}{l}\text { Proven ability to reduce high concentrations to } \\
\text { cleanup goals }\end{array}$ & $x$ & $\times$ & & $\times$ & & & & \\
\hline Destroys PCBs & $\times$ & & $\times$ & & & $\times$ & $\times$ & $\times$ \\
\hline Can be implemented in situ & & & & & & $\times$ & $x$ & $\times$ \\
\hline Concentrates PCBs, reducing disposal costs & & $\times$ & & $\times$ & $\times$ & & & \\
\hline $\begin{array}{l}\text { Effective across wide range of soil/sediment } \\
\text { characteristics }\end{array}$ & $\times$ & & & & & & & $\times$ \\
\hline Effective on inorganic co-contaminants & & & & & $\times$ & $\times$ & & $\times$ \\
\hline \multicolumn{9}{|l|}{ Limitations } \\
\hline High moisture content adversely affects treatment & $\times$ & $\times$ & $x$ & & & $\times$ & & $\times$ \\
\hline PCBs must be destroyed by another technology & & $\times$ & & $\times$ & $\times$ & & & \\
\hline Produced residuals that must be treated and/or disposed & $\times$ & & $\times$ & $\times$ & $\times$ & & & $\times$ \\
\hline Sensitive to media particle size, clay content, and/or $\mathrm{pH}$ & & $x$ & $x$ & $\times$ & $\times$ & $\times$ & & \\
\hline Not proven to treat all PCB congeners & & & $\times$ & & & $\times$ & & \\
\hline Sensitive to co-contaminants & $\times$ & & $\times$ & & & $\times$ & & \\
\hline Off-gases must be treated prior to release & $\times$ & $x$ & $x$ & & & & & $\times$ \\
\hline Often subject to negative public opinion & $\times$ & $\times$ & & & & & & $\times$ \\
\hline Volume and/or characteristic changes to treated media & & & & & $\times$ & $\times$ & & $\times$ \\
\hline Potentially affected by ambient temperature extremes & & & & & $\times$ & $\times$ & & \\
\hline Difficult to measure effectiveness of treatment & & & & & & $\times$ & & $\times$ \\
\hline Long-term monitoring required for onsite treatment & & & & & & & & $\times$ \\
\hline
\end{tabular}




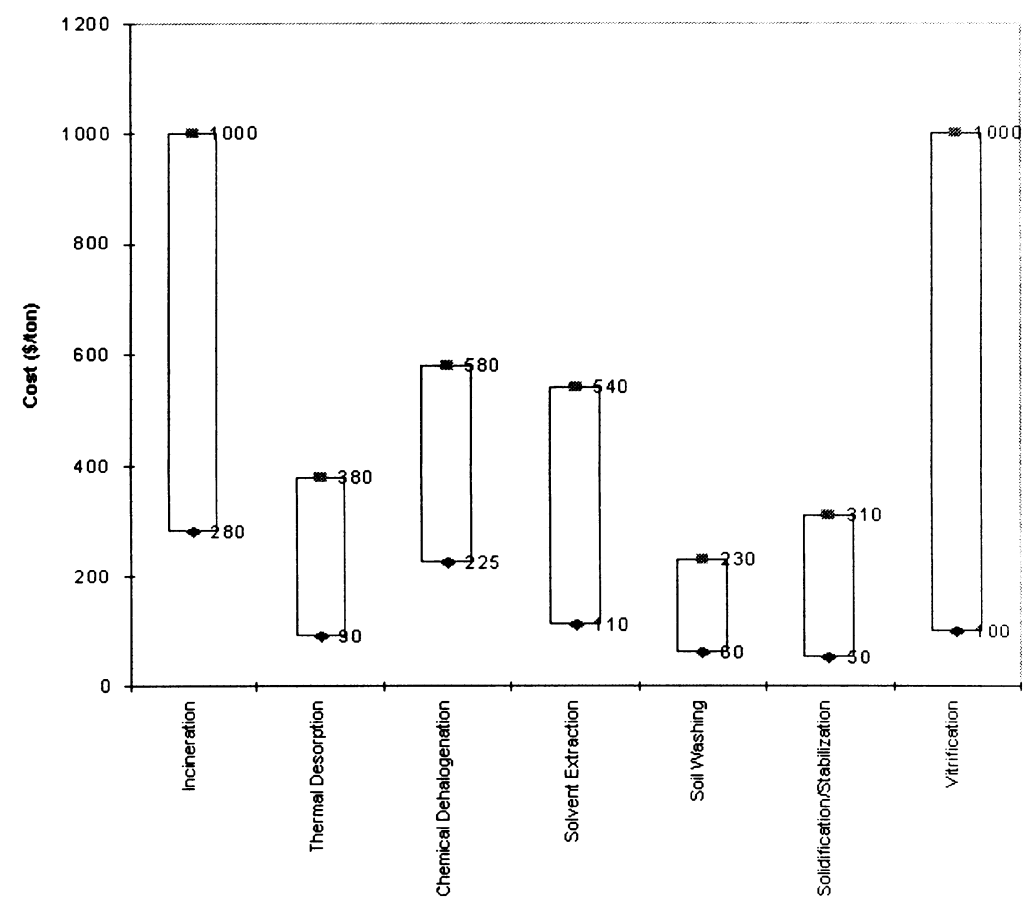

Fig. 1 Destruction costs.

mechanism, combustion stages, bottom and fly ash handling units, air emission controls, heat exchanger and exhaust stacks.

\subsubsection{Chemical waste landfills}

Are subjected to specific design regulations including topographical requirements, water monitoring for surface and ground water, leachate collection, and operating procedures on the containers (Table 1).

\subsubsection{High-efficiency boilers}

Are subjected to specific criteria for PCBs disposal. Costs are not available because boilers already on site are usually used.

\subsubsection{Municipal solid waste landfills}

Some small products containing traces of PCB may be disposed of in municipal solid waste landfills at the same costs for disposing of other nonhazardous wastes, estimated at $\$ 45$ per ton.

\subsection{Alternative methods}

An alternative method of PCB disposal can be used only if it can be demonstrated as able to destroy PCBs at a level of performance equivalent to incinerators or high-efficiency boilers.

\subsubsection{Thermal desorption}

Thermal desorption uses high temperatures to physically separate volatile and semivolatile contaminants from soil, sediment, and sludge.

Thermal desorption, typically used as a mobile technology, is generally cost-effective on wastes containing up to $10 \%$ organics and a minimum of $20 \%$ solids. The process involves materials handling, desorption, particulate removal, and off-gas treatment. Because thermal desorption concentrates PCBs, the resulting PCB residue may contain a concentration greater than 50 p.p.m., and other regulatory requirements would then need to be met (e.g. notification, transport, manifest, storage, and disposal requirements). 


\subsubsection{Chemical dehalogenation or dechlorination}

The method uses chemical reactions to remove PCB chlorine atoms from organic molecules.

An example of a chemical dehalogenation process is 'base-catalyzed decomposition' (BCD). BCD, usually used as a mobile technology, is an efficient and relatively inexpensive alternative technology for treating both PCB-contaminated equipment (e.g. transformers) and PCB-contaminated soils and sediments. This method can be used to declassify PCB-contaminated electrical equipments. Diesel fuel or natural gas is used to heat a primary reactor. Either $\mathrm{NaOH}, \mathrm{NaHCO}_{3}$, or aliphatic hydrocarbons are used as hydrogen donors. The presence of metals may affect performance (may increase the needed amounts of hydrogen). BCD can treat PCBs at almost any concentration, and laboratory research shows that BCD does not produce, and can significantly reduce, levels of chlorinated dioxins and furans.

\subsubsection{Solvent extraction}

Solvent extraction does not destroy wastes but physically separates hazardous contaminants from soil and sediment, thus reducing the volume of hazardous waste to be treated. Often an organic chemical is used as a solvent to collect and concentrate the contaminant. The process involves media preparation, contaminant extraction, solvent/media separation, contaminant collection, and solvent recycling. The contaminant extract requires further treatment, such as incineration or dehalogenation.

\subsubsection{Soil washing}

Soil washing involves mechanically mixing, washing, and rinsing soils to remove contaminants. The contaminants are removed by either dissolving them in the wash solution, or concentrating them into a smaller volume through simple particle separation. The process, often used as a mobile technology, involves soil preparation, washing, soil and water separation, wastewater treatment, and vapor treatment. Some of the process residuals may need further treatment for proper disposal. The water should be recovered and reused to the maximum extent possible (Fig. 1).

\subsection{Emerging alternative methods}

The US EPA and other researchers are currently reviewing the technologies described below. They are in the bench-scale or pilot-scale testing stages, in studies that are designed to generate additional data regarding their ability to treat PCBs

\subsubsection{Stabilization/solidification}

Waste stabilization adds a binding agent to the waste (Portland cement, cement kiln dust) to convert contaminants into a less soluble, less mobile, or less toxic form. Waste solidification adds a binding agent to the waste to encapsulate the contaminants in solid material. Both the technologies reduce the mobility of PCBs, but do not concentrate or destroy them.

\subsubsection{Plasma vitrification}

Vitrification technologies use electric plasma processes to heat and melt contaminated soil or sediment containing organic, inorganic, or radioactive contaminants, forming a rigid, glassy product when it cools. Temperatures in the process are in the range of $1000-2000^{\circ} \mathrm{C}$. The volume of the vitrified product is typically $20-45 \%$ less than the original volume of the waste. PCBs are destroyed by the high temperatures used during vitrification. Off-gas collection systems generally are needed. The scrubber water and other process components may require further treatment or disposal.

\subsubsection{Bioremediation}

Bioremediation uses micro-organisms to break down or detoxify organic compounds. Bioremediation of PCBs works best under aerobic conditions but will also occur at a slower rate in anaerobic conditions. Oxygen can be increased (e.g. through bioventing), and bioremediation can be enhanced by increasing the availability of water, nutrients, electron acceptors, and micro-organisms. PCBs with fewer chlorine atoms are more completely degraded than PCBs with a higher chlorine content, although these, too, can be 
partially degraded. Current cost information on bioremediation is limited and not adequately available at this time

\section{PLASMA PROCESSES FOR HALOGENATED COMPOUNDS}

Between the new technologies able to treat halogenated substances, the plasma-arc process appears one of the most interesting. In fact, the recent development of industrial techniques based on the use of thermal plasmas makes the incineration more efficient through the attainment of more elevated temperatures and reactivity also in large volumes with low thermal inactivity and high process flexibility. The destruction process of organic toxic substances could be, besides, used both to the aim of pure energetic recovery on those typologies of substances that give place to the final formation of hydrocarbon light fuels and for the treatment of organic substances that can be hardly destroyed in elevated environmental safety conditions. The last category also comprises the halo-methane gases used as fire extinguishers commercially named Halons. Therefore, the thermal plasma reactors offer peculiar advantages for the destruction of hazardous wastes:

- the high energy density and temperatures associated with thermal plasmas and the corresponding fast reaction times offer the potential of large throughputs in a small reactor,

- the high temperatures can also be used to obtain very high quench rates allowing the attainment of metastable states and nonequilibrium compositions

- the high heat fluxes at the reactor boundaries lead to fast attainment of steady state conditions, allowing faster start-up and shut down times than the other thermal treatments

- use of electric energy reduces gas flow needs and off-gas treatment requirements and offers control over the chemistry, including the possibility of generating saleable coproducts

- all the characteristics combined allow easy integration into a manufacturing process which generates hazardous wastes, thus permitting the destruction of the wastes at the source.

The major disadvantage of the plasma process lies in the use of electricity as energy source, which unfavorably influences the process economics. A further consideration is that the plasma processes have more parameters to control compared to traditional processes and require therefore a higher degree of automation in the process control.

\section{THERMAL PLASMA GENERATORS (PLASMA TORCHES)}

Most thermal plasmas used in materials processing are generated by electrical discharges: DC or AC discharges or high frequency induction discharges. The arc discharge provide a high density high temperature region between two electrodes, but, with the aid of a sufficiently high gas flow, the plasma may extend beyond one of the electrodes in form of a plasma jet.

In the nontransferred arch torch, the use of which is object of this paper, the two arc electrodes do not participate in the process and have the sole function of generating the plasma. Usually a plasma gas flow is required to transport the plasma energy in form of the plasma jet to the reaction region. In a few cases, the waste materials are injected directly into the arc providing some of the plasma gas; however, the interaction of corroding plasma gas components, such as chlorine, with the electrodes may lead to high erosion rates requiring frequent exchange of electrodes. Therefore, the reactants are more frequently injected into the plasma jet downstream of the electrodes. The electrodes are usually water cooled, and several designs use axial magnetic field generated around the electrodes to force a movement of the arc attachment spot at the electrode surface. Non transferred arc torches are commercially available for operation at power levels from $1 \mathrm{~kW}$ to over $6 \mathrm{MW}$. [2] Gas heating efficiency ranges from $50 \%$ to $90 \%$ increasing with flow rate. The plasma gas flow rates are higher than those for other plasma processes making off-gas treatment more expensive. Use of a nonreactive plasma gas such as argon will maximize electrode life, but at expense of energy efficiency.

\section{WASTES TREATABLE WITH NONTRANSFERRED PLASMA ARC REACTORS}

The category of the concentrated liquid organic hazardous wastes contains PCBs and similar but also 
other chemicals used for processing, e.g. paint solvent and cleaning agents. These are the most expensive to destroy [3] but represent the smallest amount of the nonradioactive wastes.

However, changing definitions of hazardous materials to include the influence of these materials on more and more of the environment (e.g. on the ozone layer in the upper atmosphere) has led to an increase in the number of liquids in this category, and processes for treatment of halogenated organic compounds. Plasma processes are particularly suited for destruction of these wastes because plasma pyrolysis is not significantly impacted by the concentration of the halogens.

\section{SPECIFIC APPLICATIONS OF PLASMA WASTE TREATMENT PROCESSES}

\subsection{Treatment of chlorinated compounds}

\subsection{1 (PCBs)}

There are several efforts in progress at various stages of their development. The most complete development of a plasma process has been performed by Westinghouse [4]. The reactor consists of a $1 \mathrm{MW}$ nontransferred plasma torch, a refractory lined hot reaction channel which exhaust the reaction products into a larger holding tank. From here they are vented to a scrubber where the acidic gases are neutralized, and then exhausted. The torch consists of two cylindrical water-cooled electrodes having the same diameter, and the plasma gas (air) is injected through a narrow gap between them (Fig. 2). A magnetic field rotates the arc-electrode attachment reducing electrode wear. Only liquid waste can be destroyed.

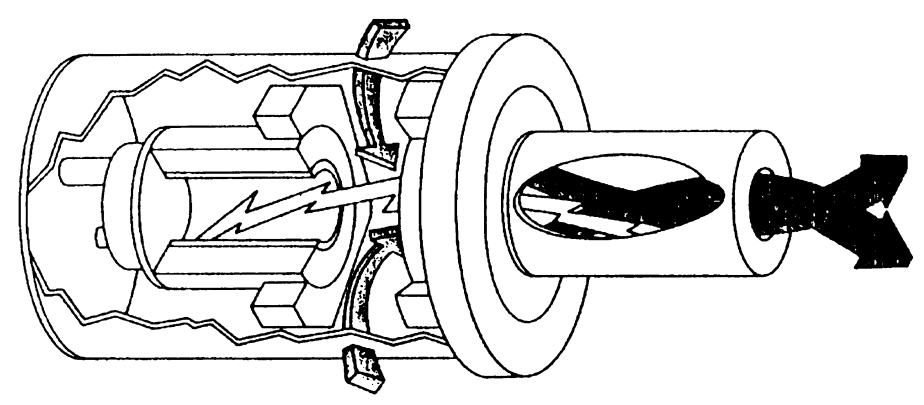

Fig. 2 Westinghouse plasma torch scheme.

The liquid waste materials (mixtures of Aroclors 1254 and 1260 in trichlorobenzene) are injected into the jet immediately downstream of the torch.

The process has been operated with various wastes, and for PCBs being destroyed at a rate of up $12 \mathrm{~L} /$ min with a torch power of $850 \mathrm{~kW}$, destruction efficiencies of $99.999996 \%$ have been attained, with particulate and acid emission well under the EPA guidelines [5].

The quality of the gaseous emission and of the waste water are constantly monitored.

The test results are summarized in Tables 2 and 3

Emission of products of incomplete combustion (PICs, specifically chlorinated dioxins and furans) were usually non detectable in both the stack gas and water effluent.

\subsection{2 $\left(\mathrm{CH}_{2} \mathrm{Cl}_{2}, \mathrm{CCl}_{4}\right)$}

Several laboratory experiences have been internationally carried out using different types of non transferred arc plasma torches. The target is to test a process able to decompose chlorinated liquid or gases and to recovery chorine without pollution of the atmosphere (Fig. 2).

For example, the decomposition of dichloromethane $\left(\mathrm{CH}_{2} \mathrm{Cl}_{2}\right)$ has been deeply investigated by the Institute of Plasma Physics of Prague [6]. The plasma is generated in water plasma torch by heating and ionization of steam produced by the interaction of the electric arc with water vortex surrounding the arc column. Experiments were carried out with a total power of the torch of $84 \mathrm{~kW}$ (Fig. 3)

The reaction chamber is made by stainless steel with an alumina tube inserted $20 \mathrm{~mm}$ downstream the 
Table 2 PCB test results

\begin{tabular}{|c|c|c|c|c|c|c|}
\hline \multirow[b]{2}{*}{ Test } & \multirow[b]{2}{*}{$\begin{array}{l}\text { Mass } \\
(\%)\end{array}$} & \multirow[b]{2}{*}{$\begin{array}{l}\text { Input } \\
(\mathrm{kg} / \mathrm{h})\end{array}$} & \multicolumn{3}{|c|}{ PCB output } & \multirow[b]{2}{*}{$\begin{array}{l}\text { DRE } \\
(\%)\end{array}$} \\
\hline & & & $\begin{array}{l}\text { Air } \\
(\mathrm{mg} / \mathrm{h})\end{array}$ & $\begin{array}{l}\text { Water } \\
(\mathrm{mg} / \mathrm{h})\end{array}$ & $\begin{array}{l}\text { Total } \\
(\mathrm{mg} / \mathrm{h})\end{array}$ & \\
\hline 1 & 14.1 & 23.9 & 0.65 & 4.08 & 4.73 & 99.9999802 \\
\hline 2 & 14.1 & 18.8 & 2.00 & 10.16 & 12.16 & 99.9999357 \\
\hline 3 & 11.5 & 19.8 & 6.96 & 18.76 & 25.72 & 99.9998701 \\
\hline 4 & 14.3 & 18.0 & 0.43 & 0.41 & 0.84 & 99.9999953 \\
\hline 5 & 12.5 & 17.5 & 0.02 & 93.12 & 93.14 & 99.9994678 \\
\hline 6 & 12.8 & 16.9 & 0.03 & 19.56 & 19.59 & 99.9998841 \\
\hline 7 & 17.5 & 26.7 & 0.33 & 0.75 & 1.08 & 99.9999960 \\
\hline
\end{tabular}

Table 3 Flared product gas parameters

\begin{tabular}{llllllc}
\hline Test & $\begin{array}{l}\mathrm{O}_{2} \\
(\%)\end{array}$ & $\begin{array}{l}\mathrm{CO} \\
(\%)\end{array}$ & $\begin{array}{l}\mathrm{CO}_{2} \\
(\%)\end{array}$ & $\begin{array}{l}\mathrm{HCl} \\
\left(\mathrm{mg} / \mathrm{m}^{3}\right)\end{array}$ & $\begin{array}{l}\mathrm{NO}_{\mathrm{x}} \\
(\mathrm{p} . \mathrm{p} . \mathrm{m} .)\end{array}$ & $\begin{array}{l}\text { Particulate } \\
\left(\mathrm{mg} / \mathrm{m}^{3}\right)\end{array}$ \\
\hline 1 & 14.0 & 0.01 & 5.5 & $\mathrm{NA}$ & 117 & 10 \\
2 & 14.5 & 0.01 & 5.0 & 43 & $\mathrm{NA}$ & 180 \\
3 & 16.5 & 0.01 & 3.0 & 68 & 96 & 12.5 \\
4 & 15.8 & 0.00 & 3.8 & 1.07 & 115 & 15.84 \\
5 & 14.0 & 0.00 & 5.1 & 2.68 & 81 & 7.60 \\
6 & 15.3 & 0.00 & 4.3 & 1.30 & 26.8 & 10.96 \\
7 & 13.3 & 0.00 & 5.2 & & & 11.9 \\
\hline
\end{tabular}

torch exit. The substance was injected into the plasma jet in the upstream part of the tube. Oxygen was added into reaction chamber to avoid production of solid carbon. The treated liquid was injected at the rate of $60 \mathrm{~cm}^{3} / \mathrm{min}$. The measured DRE was $99.9995 \%$.

To demonstrate, at industrial level: (i) the DRE with a difficult to destroy fully chlorinated compound, (ii) the stability of the plasma system upon exposure to high concentration of chlorine, (iii) the effectiveness of the scrubber for $\mathrm{HCl}$ removal, Westinghouse have carried out some tests on carbon

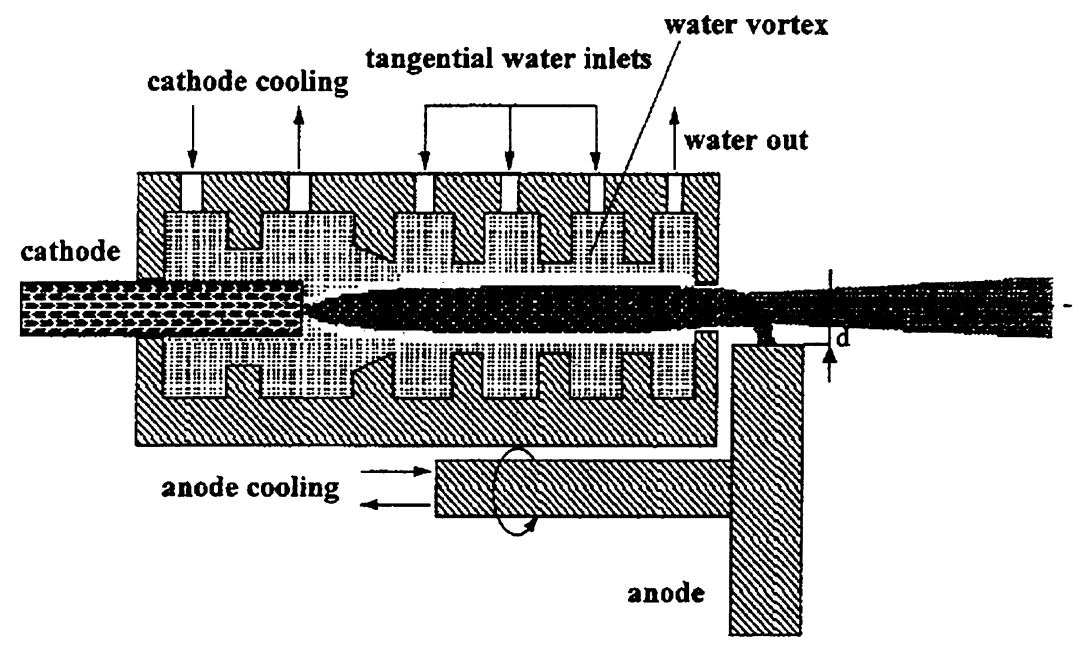

Fig. 3 Plasma torch with water vortex [6]. 
tetrachloride $\left(\mathrm{CCl}_{4}\right)$ blended with a mixture of methyl ethyl ketone $/ \mathrm{CH}_{3} \mathrm{OH} / \mathrm{H}_{2} \mathrm{O}$ fed in the plasma at a rate of $1 \mathrm{~kg} / \mathrm{min}$ of $\mathrm{CCl}_{4}$. DRE were $\geq 99.99995 \%$ based on residuals in all effluent streams. Stack emissions for $\mathrm{CCl}_{4}$ were analytically non detectable. The results are shown in Table 4 .

Table $4 \mathrm{CCl}_{4}$ test results

\begin{tabular}{|c|c|c|c|c|c|c|}
\hline \multirow[b]{2}{*}{ Test } & \multirow[b]{2}{*}{$\begin{array}{l}\text { Mass } \\
(\%)\end{array}$} & \multirow[b]{2}{*}{$\begin{array}{l}\text { Input } \\
(\mathrm{kg} / \mathrm{h})\end{array}$} & \multicolumn{3}{|c|}{$\mathrm{CCl}_{4}$ output } & \multirow[b]{2}{*}{ DRE $(\%)$} \\
\hline & & & $\begin{array}{l}\text { Air } \\
(\mathrm{mg} / \mathrm{h})\end{array}$ & $\begin{array}{l}\text { Water } \\
(\mathrm{mg} / \mathrm{h})\end{array}$ & $\begin{array}{l}\text { Total } \\
(\mathrm{mg} / \mathrm{h})\end{array}$ & \\
\hline 1 & 35.0 & 64.2 & 29.27 & 2.51 & 31.78 & 99.99995 \\
\hline 2 & 40.0 & 60.6 & 22.79 & 9.85 & 32.64 & 99.99995 \\
\hline 3 & 35.0 & 64.2 & 22.89 & 6.26 & 29.15 & 99.99995 \\
\hline
\end{tabular}

\subsubsection{Halons}

A laboratory plasma plant for the disposal of Halons is working at the Istituto di Fisica del Plasma in Milan. Several tests have been performed on different species of Halon using the torch system shown in Fig. 4. The plasma torch is operated in argon with a nominal power of $15 \mathrm{~kW}$. The flow of the injected substance was up to $2 \mathrm{slm}$ at 1 bar [7]. Particular care was dedicated to the design of the injection directly integrated in the plasma source [8]. Tests with Halon $1301\left(\mathrm{CF}_{3} \mathrm{Br}\right)$ have been reported [7]. The complete destruction of the Halon molecules is demonstrated by a large increase of signal of the cracking products and by the optical emission spectroscopy.

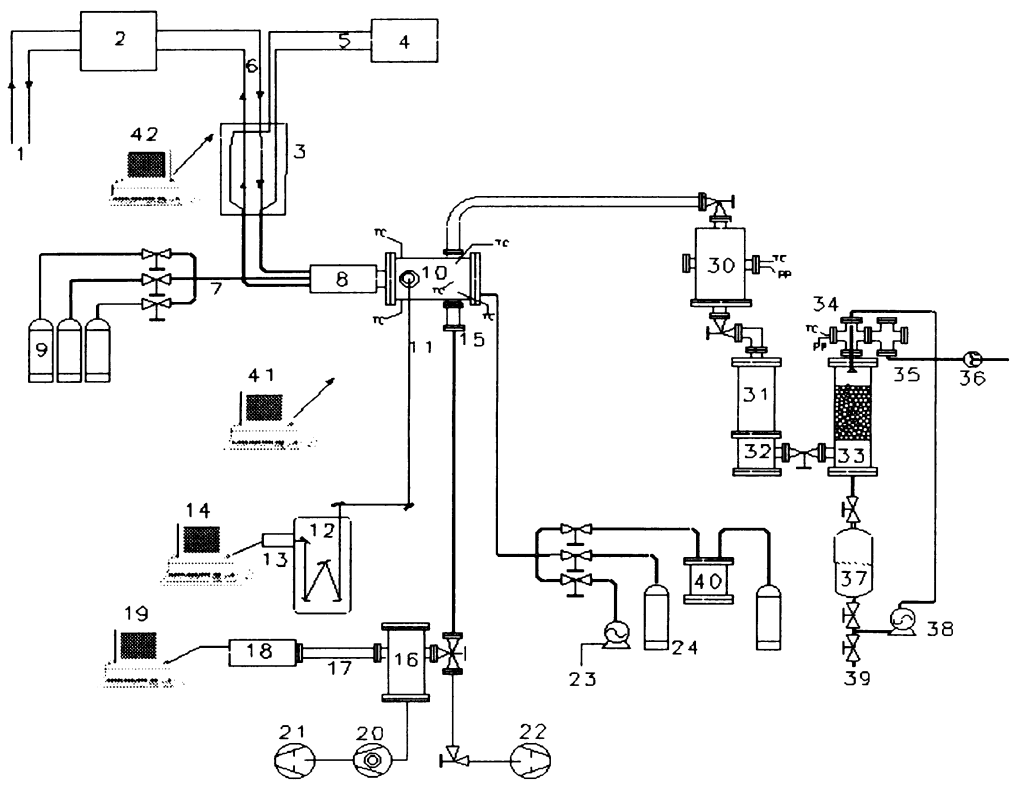

Fig. 4 IFP-CNR Milan plant layout [7].

\section{CONCLUSIONS}

The importance of toxic waste destruction increases due to environmental pollution and limited natural resources. Incineration or storage are often very hazardous. The thermal plasma technology is a promising alternative to the disposal conventional processes due to the advantages of the plasma reactors. The conversion of halogenated toxic waste in no-toxic substances by means of the plasma torch is possible. The future R\&D foresee: (i) optimisation of the cracking reactor in order to minimise the formation of metastable compounds; (ii) evaluation of the efficiency/cost rate of the process; (iii) processing of other 
types of toxic waste to optimise the destruction; (iv) process engineering; (v) transferring of the technology to the industry.

\section{REFERENCES}

1 US EPA. Management of polychlorinated biphenyl in the USA. 30 January (1997).

2 J. V. R. Heberlein. Pure Appl. Chem. 64(5), 629 (1992).

3 J. P. Woodyard. Environmental Progress 9(2), 131 (1990).

4 Westinghouse. Environmental System \& Services. Pyroplasma Technical Bulletin, July (1988).

5 J. V. R. Heberlein, W. J. Melilli, S. V. Dighe, W. H. Reed. Proceedings of the Workshop on Industrial Plasma Applications (M. I. Boulos, ed.), p. 1. Pugnochiuso, September (1989).

6 V. Brozek, M. Hrabovsky, V. Kopecky. Proceedings of the 13th International Symposium on Plasma Chemistry, pp. 1735-1739. Beijing, 18-22 August (1997).

7 F. E. Beretta, E. Vassallo, M. Cola, G. Bonizzoni. Proceedings of the 5th International Thermal Plasma Processing Conference, pp. 745-751. Saint Petersburg, 13-16 July (1999).

8 F. E. Beretta, E. Vassallo. Proceedings of the 14th International Symposium on Plasma Chemistry. Prague, 2-6 August (1999). 